\title{
Inovações Pedagógicas na Pós-Graduação na modalidade de Educação a Distância no Instituto Federal de Educação, Ciência e Tecnologia de Santa Catarina
}

\section{Pedagogical Innovations in Graduate Studies in Distance Education at the Federal Institute of Education, Science and Technology of Santa Catarina}

\author{
Roberta Pasqualli*a; Clóvis Alceu Cassaro ${ }^{\mathrm{b}}$ \\ anstituto Federal de Educação, Ciência e Tecnologia de Santa Catarina, Programa de Pós-Graduação Stricto Sensu em Educação Profissional e \\ Tecnológica. SC, Brasil. \\ ${ }^{b}$ Universidade Federal da Fronteira Sul. SC, Brasil. \\ *E-mail: roberta.pasqualli@ifsc.edu.br
}

\begin{abstract}
Resumo
O conceito de inovação, associado ao ineditismo e à utilização de tecnologias de informação e comunicação, carece de reflexões quando associado à práticas pedagógicas. Nesta direção, o texto em tela tem como objetivo apresentar a compreensão da problemática das inovações pedagógicas mobilizadas pelos professores que atuam nos cursos de Pós-Graduação Lato Sensu na modalidade de Educação a Distância no Instituto Federal de Educação, Ciência e Tecnologia de Santa Catarina (IFSC). Foi produzido por meio da pesquisa bibliográfica, documental e empírica. Tal modo de abordagem se assenta como pesquisa exploratória e descritiva, seguindo abordagem qualitativa e dialética, acompanhada por tratamento quantitativo, seguindo os movimentos e contradições próprios dos espaços educativos. Nos resultados, observa-se que as inovações pedagógicas na Pós-Graduação Lato Sensu na modalidade de Educação a Distância no IFSC estão diretamente relacionadas aos saberes docentes dos sujeitos que nela atuam e que as práticas consideradas inovadoras se opõem aos discursos de neutralidade da ação docente, são planejadas e executadas de forma a compreender que a educação é um ato político cotidiano. Como conclusões, destaca-se a importância de que se investigue o movimento inverso do que se aponta atualmente, ou seja, como as inovações pedagógicas na modalidade de Educação a Distância podem qualificar as práticas pedagógicas da educação presencial. Indica-se que se aprofundem as pesquisas e publicações acerca da temática.
\end{abstract}

Palavras-chave: Educação. Educação a Distância. Inovações.

\begin{abstract}
The concept of innovation, associated with the originality and the use of information and communication technologies, lacks reflections when associated with pedagogical practices. Therefore, the text herein aims at presenting the understanding on the problem of pedagogical innovations mobilized by professors who work in Lato Sensu Postgraduate courses in the Distance Education modality at the Federal Institute of Education, Science and Technology of Santa Catarina (IFSC). It was produced through bibliographic, documentary and empirical research. This approach is based on exploratory and descriptive research, following a qualitative and dialectical approach, accompanied by quantitative treatment, following the movements and contradictions inherent to educational spaces. In the results, it is observed that the pedagogical innovations in the Lato Sensu Postgraduate Program in the Distance Education modality at the IFSC are directly related to the teaching knowledge of the subjects who work there and that the practices considered innovative are opposed to the neutrality discourses of the teaching action, and are planned and executed in order to understand that education is an everyday political act. As conclusions, the importance of investigating the reverse movement of what is currently pointed out is highlighted, that is, how pedagogical innovations in the Distance Education modality can qualify the pedagogical practices of classroom education. It is recommended that research and publications on the subject be deepened.
\end{abstract}

Keywords: Education. Distance Education. Innovations.

\section{Introdução}

A Educação a Distância - EAD, durante muito tempo, transitou pelo espaço acadêmico brasileiro de forma periférica. Restrita a cursos profissionalizantes e supletivos, foi considerada uma educação de segunda categoria, destinada aos estudantes com baixo poder aquisitivo e pouco acesso aos recursos tecnológicos. A utilização de recursos metodológicos limitados e de processos avaliativos protocolares contribuiu para a criação, na comunidade acadêmica, de um estranhamento em torno de sua oferta.

A partir de 1996, com a publicação da Lei de Diretrizes e Bases da Educação - LDB (BRASIL, 1996), a EAD tornou-se uma modalidade de educação regular e permitiu-se sua oferta em todos os níveis e modalidades de ensino e na educação continuada (BRASIL, 1996).

O Decreto $n^{\circ}$ 2.494/98 (BRASIL, 1998) regulamentou o Art. 80 da LDB e destacou, em seu Art. $1^{\circ}$, que a Educação a distância é uma forma de ensino que possibilita a autoaprendizagem, com a mediação de recursos didáticos sistematicamente organizados, apresentados em diferentes suportes de informação, utilizados isoladamente ou combinados, e veiculados pelos diversos meios de comunicação (BRASIL, 1998).

Se, com a publicação deste decreto, por um lado, a EAD passou a ser regulamentada, por outro, carregou o status de modalidade de educação que desconsiderava o trabalho 
docente, atribuindo o bônus da aprendizagem somente aos estudantes e ao meio comunicacional.

Nessa direção, Almeida et al. (2012) destacam que as instituições de educação e seus cursos são os sujeitos do ato educativo apresentado pelo Decreto no 2.494/98 (BRASIL, 1998) e que a omissão com relação a importância do trabalho docente trouxe alguns danos à EAD. As múltiplas leituras deste decreto permitiram a criação de variadas denominações para o trabalho docente que, mesmo hoje, anos após a sua revogação, dada pelo Decreto $\mathrm{n}^{\circ}$ 5.622, de 19 de dezembro de 2005, estão cristalizadas nos espaços acadêmicos, permitindo a divisão e precarização do trabalho docente, especialmente do tutor, considerado, por muitas instituições de ensino, como aquele que apenas executa algo que já foi planejado por especialistas e está pronto para ser distribuído em larga escala.

Há que se destacar que, com o Decreto $n^{\circ} 5.622 / 2005$, houve uma evolução da compreensão da EAD como fenômeno do campo educativo, destacando suas especificidades e trazendo para o ato educativo o professor e o estudante como partícipes de todo o processo de ensino-aprendizagem. Até hoje, essa concepção marca a oferta dos cursos a distância, que se desenvolvem basicamente em modelos compostos por polos de apoio presencial, material didático produzido por professores pesquisadores, organização didático-pedagógica estabelecida por professores formadores e execução dos cursos por tutores. (BRASIL, 2005)

Outro elemento que se destaca na história recente da EAD brasileira é que, no que diz respeito ao ensino superior, a regulamentação do Art. 80 da LDB permitiu sua expansão em todo o território nacional. Esta expansão demandou infraestrutura física e lógica e também capacitação docente acelerada e repentina já que, regulamentada, exigia fazeres pedagógicos específicos e não apenas transposições do modelo presencial. Nesta direção, compreende-se que os fazeres pedagógicos do professor da EAD se materializam, também, por meio da utilização de tecnologias da informação e comunicação (TIC) já que são instrumentos que permitem a interação entre os diferentes sujeitos da educação.

Então, é como o olhar nesses e em outros desafios que cercam a EAD que a pesquisa apresentada neste texto se constituiu. Tem como objetivo apresentar uma discussão acerca das inovações pedagógicas mobilizadas pelos docentes dos cursos de Pós-Graduação Lato Sensu na modalidade EAD do Instituto Federal de Educação, Ciência e Tecnologia de Santa Catarina (IFSC).

Situando o lócus dessa pesquisa, destaca-se que a oferta de cursos na modalidade de EAD pelo IFSC buscou ampliar o acesso ao ensino público e de qualidade para pessoas que, seja por motivos geográficos ou de outra natureza, não têm acesso à educação presencial.

Por se tratar de uma instituição de educação superior, básica e profissional, pluricurricular e multicampi, com a finalidade de qualificar profissionais no âmbito da educação tecnológica, nos diferentes níveis e modalidades de ensino, o IFSC oferta cursos na modalidade de EAD por meio de programas de governo e também por meio de cursos institucionalizados ${ }^{1}$.

Atualmente, o IFSC oferece cursos de Formação Inicial e Continuada (FIC), Cursos de Formação de Formadores e Cursos de Pós-Graduação Lato e Stricto Sensu na modalidade de EAD.

Ao longo dos anos, o IFSC adotou novas formas de fazer EAD com a inserção de inovações tecnológicas e pedagógicas em seus processos de ensinar e aprender, o que tem tornado a educação mais acessível e, o destaque às inovações pedagógicas e aos saberes docentes necessários para a docência na EAD serão objeto de reflexão na sequência deste texto.

\section{Material e Métodos}

Ao fazer perguntas dessa pesquisa aos professores que atuam nos cursos de Pós-Graduação Lato Sensu na modalidade de EAD no IFSC, instigamo-os também a refletir sobre os seus fazeres profissionais. Tardif (2014) afirma que, fazer perguntas aos professores sobre seus saberes os estimula a contar a história do saber-ensinar, por meio das experiências pessoais e profissionais que foram significativas, do ponto de vista da identidade pessoal.

Ao investigar as inovações pedagógicas mobilizadas pelos docentes (tutores, professores formadores e professores pesquisadores) dos cursos de Pós-Graduação Lato Sensu na modalidade de EAD do IFSC, considerou-se que estas estão presentes no cotidiano da prática pedagógica e, embora muitas vezes, não realizadas de forma consciente, trazem para o processo de ensino-aprendizagem concepções de formação que não são neutras.

Maria Isabel da Cunha (2006), no texto "Inovações Pedagógicas: o desafio da reconfiguração de saberes na docência universitária", destaca que:

Se a concepção de formação não é neutra, característica de todo ato humano, é preciso analisá-la numa perspectiva que se afaste da concepção meramente técnica. Inclusive, é importante lembrar, que a pesquisa sobre formação de professores pressupõe a não neutralidade. Gauthier (1999) lembra, com propriedade, que cada dispositivo do olhar e da observação modifica o objeto de estudo... por isso, nunca estudamos um objeto neutro, mas sempre um objeto implicado, caracterizado pela teoria e pelo dispositivo que permite vê-lo, observá-lo e conhecê-lo. (CUNHA, 2006, p. 2).

Trata-se de uma pesquisa de abordagem se assenta como pesquisa exploratória e descritiva, seguindo abordagem qualitativa e dialética, acompanhada por tratamento quantitativo, seguindo os movimentos e contradições próprios dos espaços educativos. Foi realizada por meio de um estudo

1 Em 2013 iniciou o processo de institucionalização da EAD, aprovando em seu Conselho Superior a criação de núcleos de EAD (NeaDs) em seus 22 campus e do Centro de Formação de Professores e EAD, posteriormente renomeado para Centro de Referência em Formação e EAD (CERFEAD). 
de caso intrínseco, baseado nos conceitos de Stake (2000) que afirma que:

o estudo não é empreendido primariamente porque o caso representa outros casos ou porque ilustra um traço ou problema particular, mas porque, em todas as suas particularidades e no que têm de comum, este caso é de interesse em si. O pesquisador, pelo menos temporariamente, subordina outras curiosidades para que as histórias dos que "vivem o caso" emerjam. O objetivo não é vir a entender algum constructo abstrato ou fenômeno genérico, tal como letramento, ou uso de droga por adolescentes ou o que um diretor de escola faz. O objetivo não é construir teoria embora em outras vezes o pesquisador possa fazer exatamente isto. (STAKE, 2000, p. 437).

A pesquisa se apropriou de levantamento bibliográfico, documental e de dados empíricos para sua consecução. A coleta de dados foi realizada por meio de um questionário aplicado com o auxílio de um formulário do Google Drive, contendo 11 questões abertas que, de forma geral, versaram sobre: (a) natureza da atuação na EAD (Coordenação, Professor Formador, Professor Pesquisador e Tutor); (b) a trajetória de vida e de sua experiência profissional, a formação acadêmica e a formação específica para docência; (c) saberes fundamentais para a docência em cursos de Pós-Graduação Lato Sensu na modalidade de EAD e, (d) inserção de práticas inovadoras no cotidiano dos cursos em que atua. A pesquisa foi aprovada pela Pró-Reitoria de Pesquisa, Pós-Graduação e Inovação (PROPPI) do IFSC e os participantes assinaram Termo de Consentimento Livre e Esclarecido (TCLE) concordando com a realização da pesquisa e a publicização dos dados.

Foram encaminhados um total de 35 questionários para todos os sujeitos (Coordenação, Professor Formador, Professor Pesquisador e Tutor) que atuam nos cursos de PósGraduação Lato Sensu na modalidade de EAD do IFSC. Dos 35 questionários encaminhados, 17 respostas foram obtidas, totalizando $48,5 \%$ dos sujeitos em estudo.

Sobre os sujeitos investigados na pesquisa, nomeados por letras maiúsculas, de A a R (17 sujeitos), destaca-se que: (a) quando à variação da idade foi de 30 a 58 anos; (b) no que diz respeito à natureza da atuação na EAD observou a predominância de respostas oriundas de tutores (73\%), seguido de professores formadores (20\%) e por coordenadores (7\%); (c) o tempo de trabalho na educação varia de $27 \%$ até 13 anos, $60 \%$ até 20 anos e 13\%, com mais de 20 anos; e (d) na formação acadêmica observou-se $2 \%$ de graduados, $48 \%$ de especialistas, $30 \%$ mestres e $20 \%$ doutores.

Com relação à formação acadêmica inicial, os bacharelados em Turismo, Administração de Empresas, Engenharia Civil, Marketing e Design e as licenciaturas em Pedagogia, Letras, História, Matemática e Geografia foram citados.

\section{Resultados e Discussão}

\subsection{As Inovações Pedagógicas na EAD}

O acesso à educação é um dos fundamentos para a conquista do exercício da cidadania de modo que, sua universalização fortalece a capacidade dos sujeitos de participar de modo efetivo na tomada de decisões que os afetam enquanto cidadãos em uma sociedade democrática. Entretanto, apesar dos avanços educacionais, especialmente na última década, a Pós-Graduação Lato Sensu na modalidade de EAD ainda é desafiadora.

No Brasil, com o crescimento da oferta de vagas para a educação superior gratuita a partir do ano de 2003 e, consequentemente, do aumento das vagas para cursos de Pós-Graduação Lato Sensu houve um aumento no número de pesquisas acerca da modalidade desta modalidade e, algumas delas, apontam para a importância do reconhecimento da não neutralidade dos projetos educacionais e, especialmente da prática docente.

Pasqualli e Carvalho (2016), Silva (2016) e Ripa (2015) apresentam, em suas pesquisas, elementos que podem ser fonte para reflexões, especialmente quando se trata da não neutralidade dos processos educativos uma vez que, se não é neutra, "a profissão docente precisa estar munida de conceitos e práticas voltadas para a formação de um sujeito capaz de interagir e transformar um mundo minado de ideologias e valores". (CUNHA, 2013).

Existe a compreensão por parte de alguns estudiosos da área da educação de que o investimento na EAD é uma das estratégias para democratizar e elevar o padrão da qualidade da educação brasileira (MOROSINI, 2003). Entretanto, segundo Morés (2014), esse discurso

[...] pressupõe a superação de práticas tecnicistas, a fim de reivindicar uma formação abrangente que permita ampliar as diferentes formas de interagir a pluralidade dos diferentes mundos que, hoje, se atravessam, de modo a criar novas maneiras de educar as pessoas, para lidar não somente com o aparato tecnológico, mas com as informações advindas dos novos tipos de saberes e com pluralidade metodológica. (MORÉS, 2014, p.368).

Nesse sentido, Hernández (2000) salienta que se a inovação depende da maneira como o indivíduo interpreta um aspecto novo dentro de um sistema. Nem sempre o que é considerado inovação para uma pessoa também o é para outra. Desta forma, pode-se afirmar que a inovação possui várias concepções uma vez que,

não é a mesma coisa para quem a promove, para quem a facilita, para quem a põe em prática ou para quem recebe seus efeitos. Portanto, a definição do que se constitui uma inovação resulta da confluência de uma pluralidade de olhares e opiniões que procedem dos que têm algum tipo de relação com ela. (HERNÁNDEZ, 2000, p.19)

Embora ainda polêmico e associado ao conceito de ineditismo, o que nos interessa é o conceito de inovação apresentado por Bragnato et al. (2007) já que estes apresentam a ideia de que a inovação nasce a partir de um contexto histórico e social, é produto da ação humana e depende de tempos, lugares e circunstâncias.

Nessa direção, a inovação pedagógica não é algo abstrato, nem necessariamente sinônimo de inovação tecnológica, mas, 
sim, de uma prática que se opõe às ideias tradicionalmente admitidas e que, de acordo com Sacristán (1999), é uma ação concreta, pontual, física ou virtual, localizada num contexto de aprendizagem relativamente incomum, envolvendo aprendizes e professores, agentes do processo de mudanças, a despeito da matriz cultural (invariante).

Para Carbonell (2002), o objetivo da inovação pedagógica é

alterar a realidade atual, mudando concepções e atitudes, métodos e alterando intervenções e melhorar ou transformar, conforme o caso, o ensino e aprendendo. A inovação, por conseguinte, está associada com a mudança e tem um componente explícito ou ideológico, cognitivo, ético e oculta - afetivo. Porque os apelos à inovação subjetividade do sujeito e do desenvolvimento da individualidade, bem como as relações teoria-prática inerente ao ato educativo. (CARBONELL, 2002, p.11-12).

Considerando a concepção de Carbonell (2002), observase a importância de que os sujeitos da inovação (professores, estudantes e comunidade escolar em geral) não percam de vista a intencionalidade da inovação proposta, já que

todo ato educacional tem uma intenção e um objetivo entendese que a inovação só tem sentido se promover mudanças e impactos significativos seja em termos de posturas, de metodologias ou mesmo de concepções (LIMA, 2017, p.108).

Sendo assim, a EAD enquanto modalidade de educação de natureza inovadora reivindica melhorias para além dos aspectos de natureza tecnológica. Não basta inserir a melhor e mais avançada tecnologia se, enquanto processo pedagógico, se repetem os fazeres da educação presencial. Não basta apresentar um discurso inovador se a organização e a prática pedagógica são pouco arrojadas e o que predomina é uma visão conservadora, repetindo o que está consolidado na educação presencial sem que se ofereça riscos e tensões.

\subsection{Saberes Docentes e Inovações Pedagógicas}

As respostas aos questionamentos dos pesquisadores foram transcritas integralmente e seguem, como resultado, para discussões e reflexões.

Em um primeiro momento, destaca-se a trajetória pessoal, acadêmica e profissional dos sujeitos da pesquisa. Sendo assim, priorizou-se a reflexão acerca dos saberes fundamentais para o exercício da docência, considerando que estes, são potencializadores de ações pedagógicas inovadoras. Pôde-se observar, com destaque, as seguintes ponderações:

Como importâncias para o exercício da docência, independentemente da modalidade de ensino, considero que um planejamento orientado a resultados de aprendizagens significativas, com ricas proposições metodológicas e constantes atualizações das bases tecnológicas com ênfase da metodologia CTSA (ciência, tecnologia, sociedade e ambiente), são capazes de qualificar o ensino-aprendizagem em quaisquer instâncias educacionais pedagógicas. Minha primeira experiência como docente se deu numa escola pública estadual, ministrando aulas pro Ensino Médio. Tal experiência me faz, hoje, repensar posturas de uma educação tecnicista, conteudistas, e amplamente voltada para avaliações de resultados quantitativos dos estudantes. [...] todos os saberes de minha formação profissional têm contribuído amplamente em minha trajetória como docente, tentando não me limitar a um objeto de estudo, mas sempre em articulação interdisciplinar. Sempre há saberes que não são alcançados pelo profissional docente, cabendo-lhe uma busca ativa de estudos e pesquisas mais recentes que saem da academia. [...] todas minhas concepções formativas interferem nesse contínuo devir para a docência. (C).

Conforme pode-se observar na fala destacada e, também, em outras falas, os sujeitos investigados apresentam a importância que se deve dar, tanto aos saberes disciplinares quanto aos saberes experienciais e, aos saberes didáticopedagógicos e de conteúdo. Todas as respostas obtidas se encaminham para a importância de que haja um equilíbrio entre estes saberes, que Pasqualli (2013, p.219) destaca como sendo "os saberes da profissionalização docente".

Krahe (2008, p.4) corrobora a ideia de unidade, afirmando que numa

[...] perspectiva de que a construção da identidade profissional vai se dar no somatório do perfeito domínio dos conteúdos específicos da especialidade, acrescido de preparo básico em metodologias e técnicas pedagógicas, enfatizando a qualificação através da posse do saber da especialidade. Isto evidencia a dicotomia entre a formação da especialidade e a formação pedagógica dos futuros professores. Este modelo baseia-se no que convencionamos chamar de racionalidade técnico/instrumental e, ainda prevalece em algumas universidades europeias.

$\mathrm{Na}$ sequência da pesquisa e, caminhando ao encontro de seu objetivo principal, refletiu-se sobre a necessidade de que sejam desenvolvidos saberes específicos para a atuação como docente da modalidade de EAD. Acerca disso, destaca-se:

[...] Não há como pensar EAD hoje da mesma forma que se pensava há mais de 5 anos. Nesse sentido, é essencial conhecer a dinâmica da modalidade, ter habilidades com ferramentas e diferentes tecnologias, ser curioso e experimentar novos recursos, saber se comunicar com os alunos no meio digital, identificar tendências e compreender o perfil dos alunos, principalmente no que tange a experiência e a interação deles em um curso virtual. Esse professor deve saber se comunicar em texto, imagem, vídeo entre outros. Deve compreender o potencial de cada mídia.(A). [...] há saberes particulares que transcendem o processo de execução de currículos a distância. Saberes que precisam suprir a falta do olho no olho, das comunicações corporais, dos gestos, das manias, dos ritmos que humanizam e concretizam o processo na modalidade presencial. Dependendo do aparato tecnológico, todos/as professores/as precisam estar atentos ao processo comunicacional que, embora indireto, é intenso, precisa de solução rápida, de uma linguagem clara, cordial, cortês, com um viés psicológico de incentivo constante, aspectos que estar à dispersos nos processos presenciais. Algumas sutilezas são necessárias, além das tecnologias digitais midiáticas, há que ser atento/a à demando do/a estudante. Tais saberes são perceptivos, muitas vezes intuitivos, provindos de experiência, de vivências de inter-relação no ciberespaço. Isso dá o toque do que poderíamos chamar de pseudo-presencialidade, pois é um processo que terá caráter humanizado, proximal, em vigília. (D).

Nessa direção, Chaquime e Mill (2015) destacam alguns saberes fundamentais para a docência na modalidade de EAD: (a) Conhecimentos e saberes relativos às tecnologias digitais e ao ambiente virtual de aprendizagem; (b) Conhecimentos e saberes relativos à modalidade de educação a distância; (c) Conhecimentos e saberes relativos à linguagem e à 
comunicação escrita; (d) Conhecimentos e saberes relativos à relação ensino-aprendizagem nos Ambientes Virtuais de Aprendizagem; (e) Conhecimentos e saberes relativos ao perfil dos alunos; (f) Conhecimentos e saberes relativos aos conteúdos disciplinares; (g) Conhecimentos e saberes relativos à organização do tempo; (h) Conhecimentos e saberes relativos ao trabalho colaborativo e cooperativo; (i) Conhecimentos e saberes relativos à atuação docente virtual e (j) Conhecimentos e saberes didático-pedagógicos.

Acredita-se ser prudente destacar, também, Moore e Kearsley que, ainda em 2007, chamavam a atenção para o fato de que ser professor na modalidade de EAD requer empatia e capacidade para entender as personalidades de seus alunos, mesmo quando filtradas pelas comunicações transmitidas tecnologicamente, orientando os estudantes para que se envolvam ativamente no processo de aprendizagem, o que não vai ao encontro do que estão habituados a fazer na educação presencial (MOORE; KEARSLEY, 2007).

$\mathrm{Na}$ sequência desta pesquisa, buscou-se investigar se há tensionamentos e/ou convergências entre os saberes docentes fundamentais para a atuação em cursos presenciais e na modalidade de EAD. Acerca disto, observa-se que na modalidade de EAD:

[...] há diferenças na medida em que o ensino presencial não depende tanto da tecnologia [...]. Muda-se a forma de comunicar, mudam-se as estratégias. Há de se destacar que, no caso de EaD online, as possibilidades da internet potencializam infinitamente o acesso a informações complementares ao curso. No caso do presencial, ainda há escolas e cursos que não promovem o uso de tecnologias (ou ainda as proíbem). Fora a mediação por meio da tecnologia, o restante converge no sentido de que ambas têm como objetivo que o aluno aprenda. (A).

Para Tardif (2014), é fundamental que se considere o contexto do saber docente, afirmando ser impossível compreendê-lo fora do âmbito dos ofícios e profissões, sem relacioná-lo com os condicionantes do trabalho. É isto que tensiona e, ao mesmo tempo, aproxima a EAD da Educação Presencial. Para o autor, o saber não é uma coisa que flutua no espaço: o saber dos professores está relacionado com a pessoa e a sua identidade, com a sua experiência de vida, com a sua história profissional e com as suas relações com os alunos e seus pares e, então, a modalidade de oferta do curso é condicionada e condiciona os saberes dos docentes.

Corroborando com a discussão em tela, um dos sujeitos da pesquisa destaca que:

A modalidade, por vezes, dita regramentos avaliativos, de planejamento, de projeção da realidade. O presencial se defende do corpo a corpo, no olho no olho, enquanto o virtual se prevalece do signo escrito, imagético, de uma identidade que está dissociada pela rede. São concepções que, muitas das vezes, se separam ou se associam. Há um modelo dialético na construção de espaços virtuais de aprendizagem que antecede a intenção, que antecipa perspectivas. Fato esse que se inverte no presencial, quando a demanda vem no diálogo real, físico. São linguagens diversas, que se diferem (presencial e a distância) até nas tratativas/abordagens que são dão em fóruns, em chats, em e-mails, em mensagens dentro dos AVAs (ambientes virtuais de aprendizagem). Clareza, objetividade, sistematização de ideias são tônicas de um processo que se define e se constrói desde o processo de apresentação da unidade curricular, até as formas de explicar o passo a passo para a realização de uma tarefa/atividade avaliativa. (E).

Para Xavier e Silva (2009, p.4), quanto à lógica de comunicação na modalidade de EAD,

[...] os recursos existentes [...] dão ao professor a possibilidade de deixar de lado a lógica linear de comunicação, comum na maioria das salas de aula, onde um fala e os outros escutam. Hoje é possível, a qualquer hora e em qualquer lugar, a comunicação generalizada entre muitas pessoas, bem diferente do que acontece na aula presencial. Na EAD o pensamento pode ser expresso muitas vezes, de forma espontânea, sem as travas da autocensura. Alunos introspectivos sentem-se à vontade em suas manifestações, contribuindo para o enriquecimento do assunto em foco, o que dificilmente fariam de forma presencial.

Behrens (2013), com o olhar nos escritos de Pierre Levy destaca que, na era digital ou cibercultura, enseja-se uma prática docente assentada na construção individual e coletiva de conhecimentos e esta, propicia uma expansão da EAD nunca antes imaginada. Logo, requer que os professores se tornem intelectuais orgânicos, capazes de promover mudanças significativas, de forma a problematizar e refletir sobre a construção da cidadania, considerando os diferentes aspectos que envolvem o contexto dos ambientes culturais, raciais, históricos, de classe e de gênero.

Por fim, para investigar a relação dos saberes docentes com as experiências pedagógicas inovadoras mobilizadas pelos professores que atuam nos cursos de Pós-Graduação Lato Sensu na modalidade EAD no Instituto Federal de Educação, Ciência e Tecnologia de Santa Catarina - IFSC, buscou indagar os sujeitos da pesquisa sobre como estas experiências se materializam nas práticas cotidianas.

Os conceitos de inovação na literatura clássica, em autores como Huberman (1973), apontam a inovação como uma melhoria sensível, mensurável, deliberada, duradoura e pouco susceptível de se produzir frequentemente. Também afirmam que a inovação é uma operação completa em si mesma, cujo objetivo é fazer instalar, aceitar e utilizar determinada mudança.

Nesse sentido, Leite (2003, p. 153) destaca que:

É preciso clareza também para perceber que as inovações estão situadas na linha de tensão entre saberes e poderes. Na prática da sala de aula, da universidade, dentro do sistema de ensino tal qual como na sociedade, revelam-se poderes desiguais. E, a poderes desiguais correspondem saberes desiguais, perpetuando a escala da reprodução social com a qual todos nós podemos estar seriamente comprometidos.

$\mathrm{Na}$ fala a seguir, percebe-se um movimento contrário ao que é relatado em algumas pesquisas acerca da temática: a possibilidade aquisição de práticas exitosa da modalidade de EAD pela educação presencial

[...] a experiência com práticas inovadoras na EAD leva o tutor a construir novas práticas pedagógicas e novas metodologia também nas nossas turmas presenciais. A gente acaba transferindo para o ensino presencial e isso é muito bom para o profissional e 
muito melhor ainda para os alunos. $(\mathrm{H})$

Embora o conceito de transferência não pareça adequado neste momento, o que percebe-se nesse trecho é que as discussões, sempre acaloradas, de que a EAD se fragiliza ao transpor para si, práticas pedagógicas da educação presencial parece abrir novos horizontes para procedimentos didáticopedagógicos.

Várias foram as respostas apontando a utilização de TIC como sendo a inovação na EAD, conforme observa-se a seguir,

A utilização de recursos disponíveis em sites especializados. (L)

A inovação está no manuseio da tecnologia agregado ao conhecimento. (G)

Por ser o curso a distância, os alunos precisam dominar o conhecimento em informática e isso é inovador já que nos cursos a distância isso não é obrigatório. (I)

Busca-se em Belloni (1998) elementos para a reflexão acerca da importância que o uso das TICs gera no imaginário coletivo. A mediatização, para Belloni (1999), refere-se a escolha de um meio mais adequado de comunicação para um determinado fim, ou seja, qual ou quais os recursos tecnológicos utilizados pelo professor dão conta em maior ou menor escala de auxiliar no processo de ensino-aprendizagem.

As tecnologias digitais oferecem possibilidades inéditas e interação mediatizada - professor e estudantes, e estudantes entre si e de interatividade com materiais de boa qualidade e grande variedade, onde as formas de comunicação como redes telemáticas apresentam grandes vantagens porque permitem combinar a flexibilidade de interação humana com a independência no tempo e espaço, sem perder velocidade.

A importância das aulas presenciais também aparece como inovação na fala do sujeito investigado, conforme podese observar.

$\mathrm{Eu}$, como tutora, tento, nas aulas presenciais estabelecer um contrato didático e também dialógico com os estudantes.

Entendo que ao firmar esta aliança, tanto a metodologia quanto

o acompanhamento necessário para a aprendizagem se tornar inovadores. (J)

É importante, no processo de ensino e aprendizagem, fazê-los acreditar que a distância é um facilitador e não um elemento de distanciamento entre quem conhece e quem está a conhecer. Os estudantes podem tornar-se autodidatas e são capazes de aprender independente do tipo de modalidade de ensino, seja ele presencial ou a distância.

Emerge, assim, a necessidade de práticas pedagógicas adequadas para responder a essa realidade. Assume-se então, com Lucarelli (2015), que a inovação pedagógica é uma prática que acontece no processo de ensino e que leva a rupturas com as práticas habituais desse processo. Assim, a inovação pedagógica interrompe comportamentos que se repetem no tempo e determinam o paradigma dominante. Sob essa lógica, a inovação pedagógica se legitima pela possibilidade de relacionar novas práticas com as que existem, utilizando, para tanto, mecanismos de oposição, diferenciação ou articulação, tal como defende a autora.

Sobre a questão da interdisciplinaridade enquanto inovação pedagógica na EAD, destacou-se que, a compreensão da multiplicidade de conhecimentos necessários aos docentes no cotidiano de sua prática pedagógica é fundamental para reverter o modelo de compartimentação de conteúdo específico, comum na modalidade de EAD.

Ora, se os saberes são plurais e constituídos no cotidiano da prática pedagógica, como trancafiá-los em currículos que não permitem os seus diálogos durantes os processos de ensino-aprendizagem? Esse questionamento surge a partir da observação da fala apresentada a seguir.

De nada adianta Projetos Pedagógicos de Curso (PPC) escritos por especialistas e materiais didáticos elaborados por Doutores formados nas melhores universidades do mundo se, durante o processo de ensino-aprendizagem os conhecimentos são tratados de forma individualizada e sem observar o contexto em que são apresentados e nem o contexto de vida dos estudantes. É uma inovação pedagógica perceber que os estudantes não são desprovidos de conhecimentos prévios e necessitam conteúdos que dialoguem com o mundo que os cerca. (M)

Dialogando com a fala do sujeito M, no campo educacional, esse pressuposto epistemológico é sustentado por Fazenda (2015, p.87), que propõe que "o conhecimento interdisciplinar busca a totalidade do conhecimento [...]" e que os professores podem e necessitam construir uma atitude interdisciplinar e de parceria com o outro.

Charczuk e Arogon (2013, p.105) destacam que os “debates sobre interdisciplinaridade são recorrentes em diversos campos do saber, sendo empreendidos desde a década de 1930, período no qual começaram a se estabelecer discussões sobre a relação entre especialização e generalização do saber" e, na EAD, se fortaleceram com a inclusão de TIC como ferramentas de mediação como, por exemplo, redes sociais vídeos e tutoriais veiculados pela internet que estabelecem diferentes formas de aprendizagem. Estudantes de cursos a distância podem ser considerados o que Freitas (2015, p. 8) chama de internautas e "os internautas desenvolvem novas formas de relação com a aprendizagem, mais autônomas, nas quais os sujeitos vão guiando seus próprios processos desenvolvendo novas formas de pensamento e raciocínio". Os recursos tecnológicos são, portanto, instrumentos interdisciplinares culturais mediadores de aprendizagem que favorecem a interação entre os sujeitos (professores, tutores e estudantes), o ambiente e o conhecimento.

\section{Conclusão}

As reflexões, ora apresentadas, partem do princípio que as inovações pedagógicas na modalidade de EAD estão diretamente relacionadas aos saberes docentes dos sujeitos que nela atuam. A dimensão inovadora observada nas práticas docentes não é estável e tampouco fixa. Dependem dos saberes adquiridos durante a formação acadêmica e das compreensões da profissionalidade construídas ao longo do dinâmico e complexo exercício de constituir-se docente. 
Observou-se que as práticas consideradas inovadoras se opõem aos discursos de neutralidade da ação docente, são planejadas e executadas de forma a compreender que a educação é um ato político cotidiano.

Também destaca-se que os sujeitos investigados na pesquisa têm dificuldade de executar ideias predefinidas por outrem. A simbologia dessa dificuldade está no fato de que, quando impostas, as ideias (e os ideais) perdem sentido. Compreende-se que nem a qualidade da proposta pedagógica e nem a força da lei podem garantir que a inovação ocorra se ela não for concebida por todos os pares envolvidos no processo de ensino-aprendizagem.

Outro elemento importante para a baila da reflexão é que existe a necessidade de que os sujeitos envolvidos nos processos inovadores estejam motivados para tal. Nenhuma inovação acontece com sujeitos desmotivados e se fragiliza quando é oriundo de ações individuais. Quanto maior o número de sujeitos motivados a inovar, maior a capacidade de intercâmbio de experiências e, mais provável que a inovação seja sustentável a longo prazo.

Entende-se que as contradições devem fazer parte do processo de inovar. Quando reconhece-se as contradições é possível reelaborar as propostas e qualificá-las de forma crítica e contínua, evitando que a inovação pontual possa sabotar a necessidade de reflexão individual e coletiva acerca do processo de ensino-aprendizagem.

Destacou-se, também, a importância da interdisciplinaridade e das relações teórico-práticas estabelecidas durante a ação docente na modalidade de EAD. Percebe-se a importância que cada conteúdo tem na construção da totalidade dos conhecimentos necessários à formação de qualidade, entretanto, não de forma sobreposta, mas sim, em forma de diálogo constantemente aprimorado. Não se trata de conhecimentos fragmentados, pulverizados e nem de separar o teórico do prático. Trata-se da percepção de que as práticas interdisciplinares produzem efeitos mais efetivos na aprendizagem dos estudantes da EAD.

Para reflexão, neste momento, há que se destacar a importância de que se investigue o movimento inverso do que se aponta atualmente, ou seja, como as inovações pedagógicas na modalidade de EAD podem qualificar as práticas pedagógicas da educação presencial e, para finalizar destacase a carência de estudos acerca das inovações pedagógicas, apontando a necessidade de que novas pesquisas sejam realizadas.

\section{Referências}

ALMEIDA, M.E.B. et al. Educação a distância: oferta, características e tendências dos cursos de licenciatura em Pedagogia. In: Estudos e pesquisas educacionais. São Paulo: Fundação Victor Civita, 2012.

BEHRENS, M.A. Projetos de aprendizagem colaborativa num paradigma emergente. In: MORAN, J.M.; BEHRENS, M.A.; MASSETO, M.T. Novas tecnologias e mediação pedagógica. Campinas: Papirus, 2013. p.67-132.
BELLONI, M.L. Tecnologia e formação de professores: rumo a uma pedagogia pós-moderna? Educ. Soc., v.19, n.65, p.143-162, 1998.

BRAGNATO, M.H.S. et al. Inovações Pedagógicas na educação superior em saúde: algumas reflexões. 2007. Disponível em http:// eprints.upc.es/cidui_2006/pujades/comunicaciones_completas/ doc241.doc. Acesso em: 26 jun. 2020.

BRASIL. Lei $n^{\circ}$ 9.394, de 20 de dezembro de 1996. Estabelece as diretrizes e bases da educação nacional. Diário Oficial da União, Brasília, DF, 23 dez. 1996. Disponível em: http://www.planalto. gov.br/ccivil_03/leis/19394.htm. Acesso em: 26 jan. 2020.

BRASIL. Decreto $n^{\circ} 2.494$, de 10 de fevereiro de 1998. Regulamenta o Art. 80 da LDB (Lei no 9.394/96). Diário Oficial da União, Brasília, DF, 11 fev. 1998. Disponível em: http://portal. mec.gov.br/seed/arquivos/pdf/tvescola/leis/D2494.pdf. Acesso em: 26 jan. 2020.

BRASIL. Decreto $n^{\circ}$ 5.622, de 19 de dezembro de 2005. Regulamenta o Art. 80 da LDB (Lei no 9.394/96). Diário Oficial da União, Brasília, DF, 20 dez. 2017. Disponível em: https:// abmes.org.br/legislacoes/detalhe/88/decreto-n.-5.622. Acesso em: 26 jan. 2020.

CARBONELL, J. A aventura de inovar: a mudança na escola. Porto Alegre: Artmed, 2002.

CHAQUIME, L.P.; MILL, D. A docência virtual e saberes docentes: um estudo da tutoria na Rede E-Tec Brasil. 2015. Disponível em: https://www.revistas.uneb.br/index.php/faeeba/ article/viewFile/1823/1237. Acesso em: 26 jan. 2020.

CHARCZUK, S.B.; ARAGÓN, R. Interdisciplinaridade na Educação a Distância: uma leitura a partir da Epistemologia Genética. Schème. Disponível em: http://www2.marilia.unesp.br/ revistas/index.php/scheme/article/view/3574/2763. Acesso em: 26 jan. 2020

CUNHA, M.I. O professor universitário na transição de paradigmas. São Paulo: JM, 2013.

CUNHA, M.I.Inovações pedagógicas: o desafio da reconfiguração de saberes na docência universitária. 2006. Disponível em: http:// porteiras.r.unipampa.edu.br/portais/cap/files/2010/10/maria isabel_da_cunha_caderno_VI.pd. Acesso em: 26 jan. 2020.

FAZENDA, I. Interdisciplinaridade: história, teoria e pesquisa. São Paulo: Papirus, 2015.

FREITAS, M.T.A. Tecnologias digitais: cognição e aprendizagem. In: REUNIÃO NACIONAL DA ANPED, 37. Florianópolis, 2015. Anais... Florianópolis: UFSC, 2015.

HERNÁNDEZ, F. et al. Aprendendo com as inovações nas escolas. Porto Alegre: Artes Médicas Sul, 2000.

HUBERMAN, M. Como se realizam as mudanças em educação: subsídios para o estudo da inovação. São Paulo: Cultrix, 1973.

LEITE, D. Inovação/tensão entre poderes e saberes... Interface, v.7, n.13, p.152-1538, 2003.

LEITE, D.; CUNHA, M.I. Inovação como fator de revitalização do ensinar e do aprender na Universidade. Colet. Prog. Pos-Grad. Educ., v.4, n.12, p.79-86, 1997.

LIMA, S.M.P. Inovação pedagógica, práticas pedagógicas inovadoras e concepções docentes no macrocampo iniciação cientifica e pesquisa do PROEMI. 2017. 271f. Dissertação (Mestrado em Educação) - Universidade Federal do Rio Grande do Norte, Natal, 2017.

LUCARELLI, E. Universidad y asesoramiento pedagógico. Buenos Aires: Miño y Dávila, 2015. 
KRAHE, E.D. Mudanças de racionalidade na pedagogia universitária: obstáculos em cursos de formação de professores, 2008. Disponível em: http://www.ufrb.edu.br/ nufordes/pedagogia-universitaria?download=20:mudanas-deracionalidade-na-pedagogia-universitria. Acesso em: 26 jun. 2020.

MOORE, M.G; KEARSLEY, G. Educação a distância: uma visão integrada. São Paulo: Thomson Learning, 2007.

MORÉS, A. Cursos de pedagogia EAD: inovações presentes nos casos da UCS e UFRGS. 2014. Disponível em: http://www. ucs.br/etc/conferencias/index.php/anpedsul/9anpedsul/paper/ view/980/730. Acesso em: 26 jan. 2020.

MOROSINI, M.C. (Org.). Enciclopédia da pedagogia universitária. Porto Alegre: Fapergs/Ries, 2003.

PASQUALLI, R.; CARVALHO, M.J.S. Os saberes docentes nos cursos de licenciatura a distância em ciências naturais e matemática nos institutos federais do Brasil. Ciênc. Educ., v.22, n.2, p.523-540, 2016. doi: https://doi.org/10.1590/1516731320160020015 .
RIPA, R. Reflexiones sobre el "ser profesor" en la educación a distancia: ¿estamos frente a una desnaturalización del trabajo docente? Comunicações Piracicaba, v.22, n.3, p.75-85, 2015.

SACRISTÁN, J.G. Poderes instáveis em educação. Porto Alegre: Artmed, 1999.

SILVA, C.I. Crítica à formação profissional em Serviço Social no ensino a distância. Em Pauta, v.14, n.37, p.150-173, 2016. doi: 10.12957/rep.2016.25389

STAKE. R. E. Case studies. In: DENZIN, N.K.; LINCOLN, Y.S. Handbook of qualitative research. London: Sage, 2000. p. 435454

TARDIF, M. Saberes docentes e formação profissional. Petrópolis: Vozes, 2014.

XAVIER, R.T.O.; SILVA, J.A. Novos paradigmas nos saberes docentes da Educação a Distância. 2009. Disponível em: www. seer.ufrgs.br/renote/article/download/13948/7849. Acesso em: 26 jun. 2020. 